\title{
Research on Culture Industry Function Attributes and Position of Library in New Era
}

\author{
Li Jingyun
}

\begin{abstract}
Hubei University of Science and Technology Library, xianning, Hubei, China
928611823@qq.com
\end{abstract}

\begin{abstract}
With the historical development of library, the evolution of library function shows the features, from closed to open, from basic to pluralism, from independence to synergy, from occupation to industry attributes, which realized resource sharing, promoted function expansion, formed the business format coupling, and promoted industrial integration. And the evolution has the functional attributes of new era cultural industry, including production and consumption, valueadded, innovation-driven, industrial practice and so on. In new era, the culture prosperity and development function of library should be positioned in the unity of social and economy, the attribute function of production factors should be positioned in combination of hard factors and soft factors, and the industrial integration and development function should be positioned in the combination mode of "culture+" and "+culture".
\end{abstract}

Keywords: library, culture industry, function, position.

\section{新时代图书馆文化产业功能属性及定位分析}

李敬云

湖北科技学院图书馆, 咸宁, 湖北, 中国

928611823@qq.com

\section{摘要}

图书馆历史变迁表明，图书馆功能的演进具有从封闭到开放、从基础到多元、从独立到协同、从职业到产业的 特点, 实现了资源共享, 推动了功能扩展, 形成了业态耦合，促进了产业融合，具有生产消费、价值增值、创 新驱动、产业实践等新时代文化产业功能属性。新时代图书馆文化繁荣发展功能应定位于社会性与经济性统 一，生产要素属性功能应定位于硬要素与软要素形态，产业融合发展功能应定位于 “文化十”与 “十文化” 模 式。

关键词: 图书馆, 文化产业, 功能, 定位

\section{1.图书馆功能变迁及其特点}

图书馆的产生和发展是人类文明的产物。图书馆 的产生历史可以追溯到公元前 7 世纪的两河流域和 公元前 13 世纪我国的殷代, 19 末图书馆一词才由日 本传入我国。随着人类文明的演进, 图书馆的功能经 历了不断演进的变迁过程, 从一般的服务性职业发展 到具有服务性质的行业, 再发展到具有服务性质的产 业。

社会分工和产业融合促进了图书馆功能的演进, 这一过程具有如下特点:
第一，从封闭到开放，实现了资源共享。农耕文 明时期图书馆是封闭的，到了工业文明时期，建立了 公共图书馆, 图书馆教育功能、传播功能突出, 其社 会功能不断完善，现代文明时期图书馆社会功能进一 步强化, 互联网的出现和信息化的发展实现了资源共 享。

第二，从基础到多元，推动了功能扩展。随着人 类文明进程的推进, 图书馆功能从农耕文明时期的收 藏、研究、决策, 逐渐发展为现代文明时期的文化遗 产保存、社会教育开展、科学技术情报传递、智力资 源开发等功能, 其社会功能不断拓展和延伸。 
第三，从独立到协同，形成了业态耦合。人类文 明进程促进了图书馆部门和业务的细分，也促进了图 书馆的专门化发展，信息文明和生态文明不仅促进了 图书馆内部各部门和各业务的耦合协同服务, 促进了 以信息技术为基础, 以网络技术为支撑的 “图书馆联 盟” 新业态兴起，而且促进了图书馆与教育、文化产 业的业态耦合发展。

第四, 从职业到产业, 促进了产业融合。从古代 农耕文明到工业文明，再到现代文明，图书馆从职业 发展到行业, 再发展到产业, 促进了产业融合, 一是 图书馆为经济发展提供信息资源; 二是从图书馆中分 离出来的信息服务直接成为信息产业和文化产业的 一部分; 三是图书馆作为文化产业的重要内容, 直接 构成文化产业不可分割的一部分。

\section{2.新时代图书馆的文化产业功能属性}

图书馆的现代发展具有新时代特点, 新时代对图 书馆功能属性提出了更高的要求。党的十九大提出了 制造强国、科技强国、网络强国、教育强国等战略, 要求传统图书馆融入产业转型升级, 不仅成为生产要 素的重要组成部分, 为新时代经济社会发展提供知识、 智力支持, 而且成为文化产业的一个重要组成部分, 具有生产消费、价值增值、创新驱动和产业实践等新 时代文化产业功能属性。

\section{1. 生产消费属性}

生产和消费是产业的基本属性。从图书馆功能来 看, 图书馆的生产主要是对文化的保护、传播和传承, 表现为文化遗产保存、社会教育开展、科学技术情报 传递、智力资源开发。从知识生态学角度来看, 图书 馆的生产主要是对文化知识的创造和应用, 表现为创 造知识、集成知识、共享知识和应用知识。图书馆的 消费属性则主要表现为对文献的借阅, 对知识再生产 的购买以及相关服务的付费消费。图书馆生产和消费 的属性具有互动平衡关系, 其生产和消费就是文化产 品的供给和需求。同时, 图书馆的生产和消费属性也 具有特殊性, 主要表现在:

第一, 同步性特征。生产即消费, 消费者参与生 产, 通过咨询、查阅文献等自助方式实现 “定制化” 产品消费。

第二, 非竞争性特征。与其它产品不一样, 图书 馆产品的消费不发生所有权转移, 同时产品实体不发 生损耗, 在信息化时代, 同一产品在同一时间可供多 人消费, 只要技术条件允许, 消费就不存在拥挤现象。

第三，直接性与间接性相结合的特征。传统的咨 询、查阅文献和定制化购买是对产品的直接消费, 源 于知识创造和运用的文化产品创意和产品的文化内 涵提炼, 是对产品的间接消费, 文化产品的展示则具 有二者兼有的特点。

\section{2. 价值增值属性}

从生产要素角度来看, 图书馆创造、集成、共享 和应用的知识是文化产业的生产要素, 参与了文化产 品的生产过程和文化产业核心竞争力的构建, 具有价 值增值属性。从资本角度来看, 图书馆的生产和消费 是文化资本的重要内容之一, 布迪厄将文化资本与经 济资本、社会资本并列为三大资本 (Pierre Bourdieu, 1986), 戴维 - 思罗斯比将文化资本称为第四种资本

（D.Throsby，1998）, 资本的重要特征就是增值性。 同时, 图书馆的价值增值属性也具有特殊性, 主要表 现在:

第一, 递增性特征。知识具有外溢性和非完整性 特征, 不仅如此, 知识产品还会引致新的需求, 因此 作为生产要素的知识具有边际报酬递增的特点, 知识 边际报酬的递增决定了图书馆价值增值属性的递增 性特征。

第二, 关联性特征。作为文化资本重要内容的图 书馆的生产和消费不仅自身实现价值增值，而且与物 质资本、人力资本、自然资本协同作用，共同提升文 化产业价值增值能力, 同时文化资本以显性和隐性两 种方式向经济资本和社会资本转化, 实现增值转移, 提升经济资本和社会资本的价值增值功能。

第三, 多样性特征。图书馆的价值增值属性具有 价值增值的多样性, 不仅在经济价值上实现价值增值, 而且在社会价值上实现价值增值, 进一步提高全民文 化素质, 构建和谐社会, 促进社会进步。

\section{3. 创新驱动属性}

从图书馆的功能来看, 图书馆具有社会教育开展、 智力资源开发功能, 这是人力资本培育的重要因素, 通过知识的传递和智力资源开发, 完成文化产业人力 资本创新性和创造性特征的构建, 实现文化产业的创 新驱动发展。从知识特征来看, 图书馆的知识创造、 集成、共享和应用活动完成了知识的积累, 而知识积 累到一定程度必然引起文化产品的创意和文化产业 的创新。同时, 图书馆的创新驱动属性也具有特殊性, 主要表现在:

第一, 基础性特征。图书馆生产和消费活动不仅 提升了文化产业人力资本质量, 推动了文化产业的创 新, 而且通过人力资本创新因素的培育, 增强了其它 资本的创新能力, 其创新驱动效应具有基础性特征。

第二, 阈值性特征。图书馆生产和消费活动的创 新驱动是有阈值的, 只有当知识积累到一定程度时, 创新才会出现。从图书馆融入文化产业发展历程来看, 农耕文明时代, 作为职业的图书馆没有融入到生产行 业, 知识积累比较贫乏, 创新的出现不频繁。工业文 明时代, 作为行业的图书馆开始为产业服务, 知识积 累较为迅速, 创新的出现频率较高。现代文明时代, 图书馆融入文化产业发展, 图书馆的产业属性和信息 
化带来了知识积累的叠加效应, 创新比任何时候都来 得频繁。

第三，强值性特征。图书馆的生产和消费活动构 成文化产业的内容, 其内容成果源于对知识的创意和 再创造, 形成文化产品的内容创新、形式创新和业态 创新, 创新驱动增强价值增值的提升, 具有强值性特 征，同时信息化缩短了创新的时间间隔，加快了创新 频率。

\section{4. 产业实践属性}

市场经济的发展，促进了图书馆文化产业功能的 实践, 图书馆的主要文化产业实践表现为有偿服务、 “一馆两制”、产业业务剥离、专业图书馆的建立等。 有偿服务主要是信息咨询、信息检索、信息加工、信 息传播等, “一馆两制” 主要是在图书馆内开办信息 开发、咨询等文化产业服务实体, 产业业务剥离主要 是将文化产业服务实体从原有图书馆体制内分离出 来，专门从事诸如信息服务实业等文化产业经营公司， 专业图书馆的建立基于文化产业的产品展示和文化 传播, 如温州的中国鞋都图书馆。图书馆的产业实践 充分印证了图书馆所具有的文化产业功能属性。同时, 图书馆的产业实践属性也具有特殊性, 主要表现在:

第一，非完全产业化特征。图书馆具有文化产业 功能属性, 但图书馆公共功能属性和俱乐部产品属性 决定了图书馆的非完全产业化特征, 表现为图书馆业 务和功能的非完全产业化, 使图书馆的一部分业务和 功能始终处于公共服务领域。

第二, 产业化分离特征。产业实践表明, 图书馆 融入文化产业的途径具有多样化的模式, 从有偿服务、 “一馆两制” 到产业业务剥离、专业图书馆建立的发 展模式, 是产业化逐渐分离的过程, 这是图书馆价值 链条从纯文化价值、社会价值向经济价值延伸和转变 的过程, 也是图书馆价值链条经济功能环节独立化的 过程。

第三, “互联网+”特征。“互联网+” 的出现, 深化了图书馆产业化的属性和产业化的内容, 也使图 书馆能够从多个方面融入文化产业发展, 在文化产业 项目选择和文化产品研发源头融入文化创意, 注入文 化内容, 在文化产业项目打造和文化产品生产环节融 入文化符号, 在文化产品推广和消费环节提供文化展 示, 深化特色文化印象。

\section{3.新时代图书馆的文化产业功能定位}

\section{1. 文化繁荣发展功能定位：社会性与经济 性统一}

文化产业具有社会性和经济性双重特征, 是社会 性与经济性的统一体，《文化部 “十三五” 时期文化产 业发展规划》明确提出要进一步坚定文化自信, 增强 文化自觉, 坚持创新驱动, 推动文化产业转型升级、
提质增效, “十九大” 报告提出要推动社会主义文化 繁荣兴盛, 要完善公共文化体系, 推动文化产业发展, 因此文化繁荣离不开文化产业的发展, 文化产业的发 展是文化繁荣的重要内容。图书馆是文化产业社会性 与经济性相统一的重要载体, 其文化繁荣发展功能应 定位于社会性与经济性的统一。首先, 图书馆的教育 功能决定文化繁荣的性质。新时代图书馆应把培育和 践行社会主义核心价值观，培养担当民族复兴大任的 时代新人作为首要任务, 增强文化自信, 凝聚中国精 神, 提高国家文化软实力。其次, 图书馆的公共服务 性质增强公共文化体系的建设。图书馆在推动资源优 化配置、推动公共文化服务均衡发展中具有重要作用, 特别是 2017 年《中华人民共和国公共图书馆法》的 颁布, 以法律形式保证和规范了公共图书馆服务于公 共文化体系建设的功能。最后, 图书馆的资源融合创 新推动文化产业发展。科技创新和社会经济的发展不 仅激活和创新了馆内资源, 而且通过互联网平台增加 了资源的汇集速度，资源的融合创新使图书馆由信息 共享空间向学习空间、知识空间、创客空间发展, 为 文化产业发展提供知识资源和智力支撑, 创新了图书 馆的经济属性功能。

\section{2. 生产要素属性功能定位: 硬要素与软要 素形态}

图书馆文化产业功能属性决定了图书馆是生产 要素载体。文化产业属于创新密集型产业, 其创新的 来源在于技术、信息、知识、文化资源。实证研究表 明, 资本要素相比劳动力要素和文化要素, 是文化产 业发展投入要素的关键，但存在明显的投入穴余(高 军、吴欣桐,2016), 这说明文化产业生产要素投入配 比不合理, 劳动力要素和文化要素是文化产业发展的 资源约束。文化产业各细分行业全要素生产率研究表 明, 文化产业各行业生产率不均衡, 图书馆全要素生 产率排第三, 为 1.095(钟廷勇、周磊、安烨, 2014), 因此, 图书馆对整体文化产业的贡献较大, 它所具有 的技术、信息、知识、文化资源是文化产业的重要生 产要素, 图书馆生产要素属性功能应定位于硬要素与 软要素形态。首先, 图书馆的信息网络和交流空间为 文化产业发展提供硬要素。图书馆由 1.0 时代到 2.0 时代, 再发展到今天的 3.0 时代, 其信息网络环境不 断升级, 以 web3.0 技术为核心的技术网络使个性化 服务、智能服务不断优化, 开放程度、资源融合程度 大大提升, 为文化产业发展的资源获取和信息传递提 供了硬件条件，同时图书馆 3.0 时代拓展了交流的实 物空间和虚拟空间, 激发了社区活力, 推动了文化产 业创客空间的建立。其次，图书馆的信息、知识、文 化资源具有软要素属性。文化产业发展除了硬要素外, 信息、知识、文化资源是文化产业发展的软要素, 软 要素是推动文化产业发展的关键, 与硬要素相比, 它 不仅具有边际报酬递增的特点, 使文化产品价值不断 提升, 而且还具较强的渗透性和外溢性效应, 通过内 渗丰富文化产品内容, 通过外溢创新文化产品品种。 
最后, 图书馆硬要素与软要素的结合促进了要素的文 化产业化转换。信息网络、交流空间与信息、知识、 文化资源的结合，促进了要素向文化信息产业、文化 创意产业、文化传播产业、产品文化叙事的转换，推 动了文化资源的创造性转化发展, 催生了新兴的文化 产业类型。

\section{3. 产业融合发展功能定位: “文化十”与 “十文化” 模式}

产业融合是不同产业或同一产业不同行业相互 渗透、相互交叉, 最终融合为一体的动态发展过程, 产业融合是现代产业经济发展的新趋势, 技术创新、 产业竞合关系和产业规制的放松，促进了产业融合发 展。技术创新推动了图书馆与传统和现代文化产业的 相互交叉，产业的竞合关系使传统的图书馆与文化产 业相互渗透, 促进了图书馆的文化要素产业化转换和 文化产品的图书馆平台传播展示, 图书馆服务功能优 化升级和文化产业发展的政策支持，放松了二者交叉、 渗透的边界管制，并促进了图书馆专业化服务的产业 化分离、基于文化产业的专业化图书馆的建立以及产 品的文化内涵提升, 因此图书馆产业融合发展功能应 定位于 “文化+”与 “十文化” 模式。首先, 图书馆 具有“文化+”融合模式功能属性。《文化部“十三五” 时期文化产业发展规划》明确提出要通过 “文化十” 的方式创新文化产业发展, 图书馆在推动文化产业与 制造、建筑、设计、信息、旅游、农业、体育、健康、 教育等相关产业融合发展中具有网络技术、文化资源 和创意智力功能和作用。其次, 图书馆具有 “十文化” 融合模式功能属性。图书馆通过资源专业化和特色化 的整理创新，形成和丰富 “十企业文化”、“十绿色文 化”、“十创意文化”、“十品牌文化”、“十特色文化” 等模式的核心内容, 提升企业形象, 增强企业社会责 任感, 突出产品特色, 强化产品文化叙事, 提升品牌 价值。最后, 图书馆 “文化+”与 “十文化” 模式功 能的结合促进了文化产业生态的创新发展。图书馆 “文化 + ”与 “十文化” 模式功能的结合, 不仅推动 了图书馆要素在链条前端、中端、末端的相向渗透和 延伸, 促进了文化产业链条的长度延伸、宽度延展和 内容优化，而且促进了文化产业的传播、接受和消费， 增强了传播的有效性, 消费者的认知度和获得感, 扩 大了文化产品消费市场, 增强了文化产业的经济效益 和社会效益, 从而形成和优化了文化产业发展的生态 环境。

\section{4. 结论}

历史变迁表明, 图书馆功能从封闭走向开放, 实 现了资源共享; 从基础到多元, 推动了功能扩展; 从 独立到协同，形成了业态耦合; 从职业到产业，促进 了产业融合。这一过程就图书馆功能属性扩展的过程。 新时代, 随着社会分工和产业融合的发展, 图书馆具 有文化产业属性，表现为生产消费、价值增值、创新 驱动、产业实践等文化产业特点。根据图书馆文化产
业功能属性特点, 新时代图书馆文化产业功能属性定 位在于: 文化繁荣发展功能应定位于社会性与经济性 统一, 生产要素属性功能应定位于硬要素与软要素形 态, 产业融合发展功能应定位于 “文化十” “ “十文 化”模式。

\section{REFERENCES}

[1] Huang Zong-zhong.(2011)Giving full play to library function. Library Tribune,31:14-22.

[2] Yuan Bingjie,Luo Xianchun, Yao Ming.(2017) The Library Science Thoughts Influenced by the Culture Changes of the Contemporary Times (1978 ).Research on the Library Scirnce,369:2-5.

[3] Gao jun,Wu xintong.(2016)Study on Factor Input and Development Effect of Cultural Industry. Journal of Southwest Mizu University(Humanities and Social Scirnce),37:165-169.

[4] Xia Haoling and Jia Ping.(2018) Innovative Practical Research and Thinking on Library Providing Information Services to Industries. Library and Information Service(Semi-Monthly),62:47-55.

[5] Liu Junjun.(2018)Cultural and Creative Productsthe New Element of Future Library Development. Journal of Library Scirnce,40:18-21.

[6] Li Jing-yun(2020)Analysis of Coupling Mechanism of Library Development. Journal of Hubei University of Science and Technology,40:67-71.

[7] Deng Yin-hua.(2021) Participation of Rural Libraries in Rural Revitalization Strateg:Realistic Background, Function Orientation and Promotion Strategies. Library Theory and Practice,252:25-30.

[8] Yang Fan.(2021) Research on the Innovative Development Model of Public Library under the Background of Cultural Tourism Integration. Journal of Library Scirnce,43:10-12. 